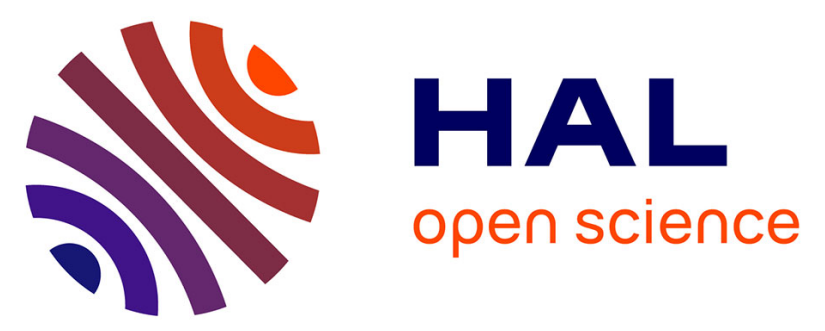

\title{
Efficient Immobilization of Tyrosinase Enzyme on Layered Double Hydroxide Hybrid Nanomaterials for Electrochemical Detection of Polyphenols
}

\author{
Asma Soussou, Ibtissem Gammoudi, Fabien Morote, Adel Kalboussi, Touria \\ Cohen-Bouhacina, Christine Grauby-Heywang, Zouhair M. Baccar
}

\section{To cite this version:}

Asma Soussou, Ibtissem Gammoudi, Fabien Morote, Adel Kalboussi, Touria Cohen-Bouhacina, et al.. Efficient Immobilization of Tyrosinase Enzyme on Layered Double Hydroxide Hybrid Nanomaterials for Electrochemical Detection of Polyphenols. IEEE Sensors Journal, 2017, 17 (4), pp.4340-4348. 10.1109/JSEN.2017.2709342 . hal-01565702

\section{HAL Id: hal-01565702 \\ https://hal.science/hal-01565702}

Submitted on 20 Jul 2017

HAL is a multi-disciplinary open access archive for the deposit and dissemination of scientific research documents, whether they are published or not. The documents may come from teaching and research institutions in France or abroad, or from public or private research centers.
L'archive ouverte pluridisciplinaire HAL, est destinée au dépôt et à la diffusion de documents scientifiques de niveau recherche, publiés ou non, émanant des établissements d'enseignement et de recherche français ou étrangers, des laboratoires publics ou privés.

\section{다(1)(2)}

Distributed under a Creative Commons Attribution - ShareAlikel 4.0 International 


\title{
Efficient Immobilization of Tyrosinase Enzyme on Layered Double Hydroxide Hybrid Nanomaterials for Electrochemical Detection of Polyphenols
}

\author{
Asma Soussou, Ibtissem Gammoudi, Fabien Moroté, Adel Kalboussi, Touria Cohen-Bouhacina, \\ Christine Grauby-Heywang, and Zouhair M. Baccar
}

\begin{abstract}
Gold screen-printed electrodes coated with thin films of layered double hydroxides containing cobalt and aluminium $\left(\mathrm{Co}_{1.57} \mathrm{Al}(\mathrm{OH})_{\mathbf{X}} \mathrm{SO}_{4}\right.$, shortened as $\left.\mathrm{CoAl}\right)$ have been investigated for the design of an electrochemical tyrosinasebased biosensor used for the detection of a complex mixture of polyphenols extracted from green tea. Physicochemical analyses show that the resulted biosensor exhibits very attractive characteristics: a high sensitivity, a large dynamic range (up to $\left.1000 \mathrm{ng} \cdot \mathrm{mL}^{-1}\right)$, and very low limits of detection $\left(0.33 \mathrm{pg} . \mathrm{mL}^{-1}\right.$ and $0.03 \mathrm{pg} . \mathrm{mL}^{-1}$ for oxidation and reduction, respectively).
\end{abstract}

Index Terms-Atomic force microscopy, electrochemical biosensor, layered double hydroxide, polyphenols, tyrosinase.

\section{INTRODUCTION}

$\mathbf{O}$ VER the past 10 years, antioxidant properties of polyphenols attracted an increasing interest of different researchers and food manufacturers [1], [2]. Polyphenols are in abundance in diet, being present in various fruits or vegetables, but also in tea or wine. They play a probable role in the prevention of various diseases associated with oxidative stress, such as cancers or cardiovascular and neurodegenerative diseases [3]-[5]. Consequently, very intensive studies have been conducted to develop innovative methods of detection, improving current ones based on chemical analysis, these last ones being time-consuming and requiring usually pretreatment steps. In this context, many biosensors have been developed for phenol determination using different enzymes: superoxide dismutase [6], laccase [7], [8], and horseradish peroxidase $[9]-[11] \ldots$

This work was supported by the Tunisian Ministry of Higher Education and Scientific Research Funding. The associate editor coordinating the review of this paper and approving it for publication was Dr. Chang-Soo Kim. (Corresponding author: Ibtissem Gammoudi.)

A. Soussou is with the Laboratoire Ondes et Matiere d'Aquitaine (LOMA), Universite de Bordeaux, UMR 5798-CNRS, 33405 Talence Cedex, France, the Laboratoire de Microélectronique et Instrumentation, LR13ES12, Université de Monastir, Monastir 5019, Tunisia, and also with the Nanobioengineering Group, National Institute for Research and Physicochemical Analysis, Sidi Thabet 2020, Tunisia.

I. Gammoudi is with the Cellul de Transfert NanoPhyNov, Laboratoire Ondes et Matiere d'Aquitaine (LOMA), Universite de Bordeaux, UMR 5798CNRS, 33405 Talence Cedex, France (e-mail: gammoudisensor@gmail.com).

F. Moroté, T. Cohen-Bouhacina, and C. Grauby-Heywang are with the Laboratoire Ondes et Matiere d'Aquitaine (LOMA), Universite de Bordeaux, UMR 5798-CNRS, 33405 Talence Cedex, France.

A. Kalboussi is with the Laboratoire de Microélectronique et Instrumentation, LR13ES12, Université de Monastir, Monastir 5019, Tunisia.

Z. M. Baccar is with the Nanobioengineering Group, National Institute for Research and Physicochemical Analysis, Sidi Thabet 2020, Tunisia.
Fungal tyrosinases are also widely used, these enzymes catalyzing the oxidation of monophenols and o-diphenols to quinones in the presence of oxygen [12]. They present indeed attractive properties: effectiveness in biosynthesis, capacity of phenols removal from various samples and high capacity of detection and quantification of phenols [13]. In addition, the detection by tyrosinase-based biosensors is not limited to pure phenol compounds, some biosensors showing their efficiency in the case of more complex mixtures of polyphenols such as those found in tea extracts [14]-[17].

Different approaches have been developed for the immobilization of tyrosinase: silica sol-gel composite films [18], tyrosinase-modified boron-doped diamond electrodes [19], [20], tyrosinase entrapped in an agarose-guar gum [21], glassy carbon electrode modified by gold nanoparticles [22], tyrosinase- $\mathrm{FeO}_{3}$ nanoparticles-chitosan [23], use of polyaniline-carbon nanofibers or nanotubes [24]-[27], diazonium salt [17] or titania sol-gel matrix [28] ...

Among host matrixes already used for the immobilization of enzymes recognizing polyphenols [6]-[11], [18]-[30], Layered Double Hydroxide (LDH) nanomaterials are attractive candidates for electrochemical analysis in general and for enzyme immobilization [31], [32], since they exhibit many advantageous features in the development of hybrid biomaterials. LDHs are an unusual family of layered materials consisting of positively charged layers with charge balancing anions inserted between these layers. Their chemical composition is $\left[\mathrm{M}_{1-\mathrm{x}}^{\mathrm{II}} \mathrm{M}_{\mathrm{x}}^{\mathrm{III}}(\mathrm{OH})_{2}\right]^{\mathrm{x}+} \mathrm{A}_{\mathrm{x} / \mathrm{n}}^{\mathrm{n}-}\left(\mathrm{H}_{2} \mathrm{O}\right)_{\mathrm{y}}$, where $\mathrm{M}^{\mathrm{II}}$ and $\mathrm{M}^{\mathrm{III}}$ represent di- and trivalent metal ions and $\mathrm{A}^{\mathrm{n}-}$ is the interlayer anion. Their particular structure is responsible for specific properties, such as their high ion exchange capacity or their encapsulation ability. At last these compounds exhibit a high biocompatibility, a parameter particularly important in the context of enzyme immobilization [33]. Incidentally, the immobilization onto LDHs films of different kinds of biomolecules, such as amino acids [34] or DNA [35] have been also successfully experimented. In the case of enzymes, LDHs properties allow an enzyme immobilization respecting its native conformation, without affecting active sites, and thus reducing any inhibition effect [32]. They are also particularly welladapted to the design of electrochemical biosensors [31]-[33]. Applications of this kind of material have been already proposed in the case of antibodies and enzymes [36]-[39]. In the case of tyrosinase, hybrid materials made of chitosan and LDHs were described [40]. Functionnalization of glassy 
carbon electrode by tyrosinase- $\mathrm{MgAlCO}_{3} \mathrm{LDH}$ was also reported [15].

Moreover, the chemical nature of LDH material could also influence the enzymatic activity. In the case of tyrosinase, previous studies showed that this enzyme is activated in the presence of cobalt or zinc and inhibited in the presence of nickel [41], leading us to use a LDH material containing cobalt $\left(\mathrm{Co}_{1.57} \mathrm{Al}(\mathrm{OH})_{\mathrm{X}} \mathrm{SO}_{4}\right.$, shortened hereafter as $\left.\mathrm{CoAl}\right)$ for its immobilization [38]. At last, the electrochemical behavior of cobalt-based LDHs is well-documented, cobalt being characterized by excellent electrochemical properties [32], [42].

In this context, our approach consists in the building a biosensor based on $\mathrm{CoAl} \mathrm{LDH} /$ tyrosinase in order to take advantage of cobalt properties mentioned above. Our work includes the physicochemical characterization of $\mathrm{CoAl}$ $\mathrm{LDH}$, followed by the determination, using Atomic Force Microscopy (AFM), of optimal experimental parameters for the elaboration of LDH thin films suitable for tyrosinase immobilization. Surprisingly AFM is rarely used, despite the fact that it is well-adapted to this context. On the whole the experimental procedure is simple and inexpensive. Finally, the electrochemical properties of the hybrid tyrosinase-CoAl LDH were evaluated in terms of sensitivity and limit of detection for the recognition of polyphenols of green tea, by cyclic voltammetry measurements performed using gold screen printed electrodes (AuSPEs). The choice of these electrodes is justified by important features such as disposability, low cost, mass production and miniaturization possibilities [43], all necessary for the potential development of a biosensor on a large scale. This study shows finally that the elaborated biosensor is highly sensitive to the presence of polyphenols.

\section{Materials And Methods}

\section{A. Materials}

$\mathrm{CoCl}_{2}, \mathrm{AlCl}_{3}$ and $\mathrm{Na}_{2} \mathrm{SO}_{4}$ salts, $\mathrm{NaOH}$, glutaraldehyde, tyrosinase from mushroom (activity $\geq 1000$ units $/ \mathrm{mg}$ ), $\mathrm{K}_{3} \mathrm{Fe}(\mathrm{CN})_{6}, \mathrm{~K}_{4} \mathrm{Fe}(\mathrm{CN})_{6} .3 \mathrm{H}_{2} \mathrm{O}$ and phosphate buffered saline tablets (PBS, $10 \mathrm{mM}, 0.137 \mathrm{M} \mathrm{NaCl}, \mathrm{pH}$ 7.4) were purchased from Sigma-Aldrich. Mixture of polyphenols of green tea was provided by MP Biomedicals LLC (France). This mixture (product number 193756), chosen as a model of mixtures met in the realistic conditions of the planned biosensor usage, contains catechins and derivatives [44]. Muscovite mica substrates for AFM experiments were purchased from Electron Microscopy Sciences (USA). Ultrapure Millipore water ( $\mathrm{pH} 6$, resistivity higher than $18.2 \mathrm{M} \Omega$ ) was used for the preparation of solutions (LDH synthesis, buffer...) and rinsing steps. AuSPEs (with carbon auxiliary electrode and silver reference one) were purchased from Metrohm (ref. 061208210).

\section{B. LDH Synthesis and Characterization}

CoAl-LDH synthesis was made by the co-precipitation method, described in details elsewhere [37], [38]. Briefly, $100 \mathrm{~mL}$ of an aqueous solution of $\mathrm{CoCl}_{2}(0.1 \mathrm{M})$ and $50 \mathrm{~mL}$ of an aqueous solution of $\mathrm{AlCl}_{3}(0.1 \mathrm{M})$ were mixed drop by drop under stirring (1250 rpm) at $65{ }^{\circ} \mathrm{C}$ for $1 \mathrm{~h}$. During mixing, $\mathrm{pH}$ was kept constant at 11 by adding a basic solution of $\mathrm{NaOH}$
$(2 \mathrm{M})$ and $\mathrm{Na}_{2} \mathrm{SO}_{4}(0.25 \mathrm{M})$. After a maturation period $(16 \mathrm{~h})$, CoAl LDHs were filtered, washed with ultrapure water, dried at $100^{\circ} \mathrm{C}$ during $24 \mathrm{~h}$, and finally crushed in nanoparticles. Powder X-ray diffraction (XRD) measurements were performed on a Panalytical X'Pert Pro diffractometer using $\mathrm{CuK} \alpha$ radiation $(\lambda=1.5406 \AA$ ) at $40 \mathrm{kV}, 30 \mathrm{~mA}$. Scanning was performed from $5.000^{\circ}$ to $80.000^{\circ}$ with a step of $0.016^{\circ}$.

Fourier Transform Infra-Red (FTIR) spectra of LDHs (in powder) were recorded using a Perkin Elmer spectrophotometer in reflexion mode in the $4000-400 \mathrm{~cm}^{-1}$ range. Final spectra exhibited here correspond to the average of 10 independent spectra. Raman spectra of LDHs were recorded in the $2500-50 \mathrm{~cm}^{-1}$ spectral range, by using a Thermo Scientific DXR Raman microscope (confocal depth of $1.7 \mu \mathrm{m}$, spatial resolution of $540 \mathrm{~nm}$ ) with an excitation wavelength of $532 \mathrm{~nm}$. Final Raman spectra were obtained by the addition of at least 3 independent spectra with an acquisition time of 5 to $7 \mathrm{~s}$ each.

\section{Hybrid CoAl-LDH/Tyrosinase Surfaces and AFM Study}

Surface modification parameters and conditions, was firstly studied using Self Assembled Method (SAM) onto mica film then reported to Au-SPEs. AFM techniques were used for studying the homogeneity and the modification steps of the Au-SPEs surface. For this purpose, CoAl LDH was solubilized in ultrapure water at a final concentration ranging from 0.50 to $2.50 \mathrm{mg} \cdot \mathrm{mL}^{-1}$. This aqueous solution was homogenized by quick stirring with vortex, and 15 to $20 \mu \mathrm{l}$ were deposited at the surface, such a volume being enough to cover electrodes surface without exceeding their edges. Surfaces were then dried in air and rinsed with ultrapure water for eliminating unbounded LDH from the surface.

The second step of the phenol-biosensor construction consisted in auto-assembling tyrosinase over the modified electrodes. Tyrosinase was firstly solubilized in PBS buffer solution (at a $\mathrm{pH}$ 6.6, included into the stability range of this enzyme [18], [26], [27], [45]) at a concentration of $1.5 \mathrm{mg} \cdot \mathrm{mL}^{-1}$. Then, a drop of $10 \mu \mathrm{L}$ of this solution was deposited on the previous modified surfaces. After incubation at $37{ }^{\circ} \mathrm{C}$ during $10 \mathrm{~min}$, surfaces were overnight-stored in saturated PBS (pH 7.4) atmosphere at $4{ }^{\circ} \mathrm{C}$, in order to avoid getting dry. Finally, immobilized enzyme molecules were reticulated in saturated glutaraldehyde atmosphere for 8 minutes and surfaces were rinsed carefully with PBS for removing enzyme excess.

Surface modifications at the different functionnalization steps were studied using two different AFM setups: a MultiMode NanoScope II apparatus (AFM imaging) and a Bioscope II, mounted on an IX71 Olympus inverted optical microscope and operating with the NanoScope $\mathrm{V}$ controller (Veeco-Brucker, Santa Barbara, CA). All data presented in this paper were generated with the same cantilever (with a nominal spring constant of about $40 \mathrm{~N} . \mathrm{m}^{-1}$ ) and at a scan rate between 0.1 and $0.5 \mathrm{~Hz}$. AFM study was made under ambient conditions ( $\mathrm{T}=20-21{ }^{\circ} \mathrm{C}$ ), in air, and in tapping mode to preserve sample integrity [46]. For each experiment, three independent samples and different zones were scanned. The surface roughness was obtained with the NanoScope 

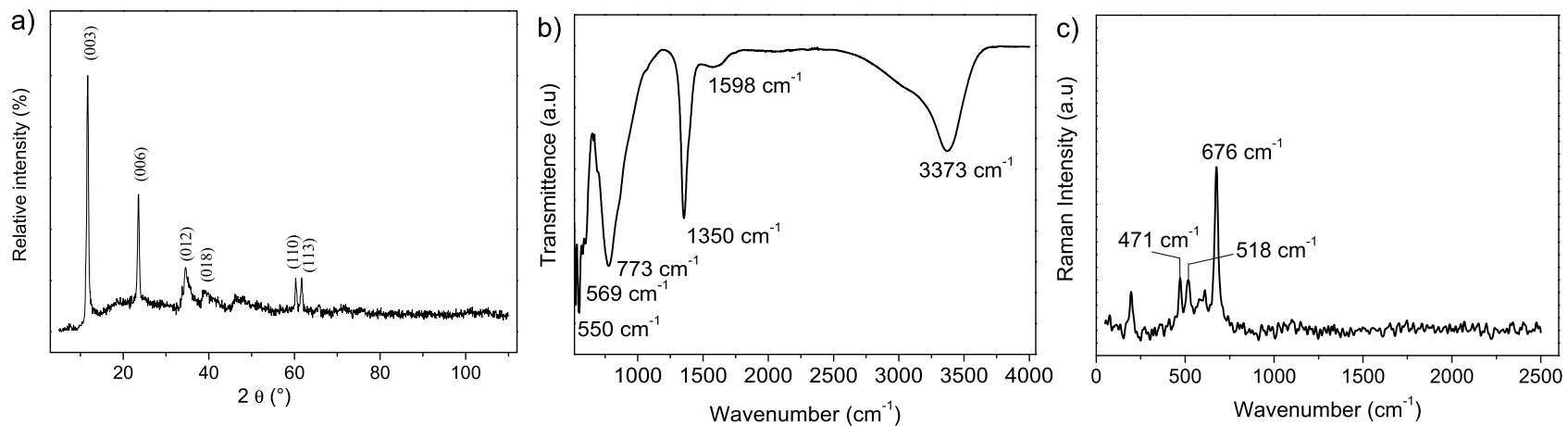

Fig. 1. (a) XRD pattern of CoAl-LDH. The Miller indices of some selected reflections are shown above the peaks. (b) FTIR spectrum. (c) Raman spectrum of CoAl-LDH.

setup by the average of 5 to 10 measurements for each scan. Scratching experiments were performed using contact mode (typically on a surface of $1 \mu \mathrm{m} \times 1 \mu \mathrm{m}$ ), the force applied onto the sample being higher than typical force used for imaging (around $80 \mathrm{nN}$ ). Height sections performed between intact and scratched areas gave the thickness of the film, assuming that the lower surface is mica.

\section{Cyclic Voltammetry $(\mathrm{CV})$}

Voltammetric measurements were carried out using an Ivium CompactStat 10800 (Portable Electrochemical and Impedance Analyzer) at room temperature. A three cell conventional system was used, including a gold working electrode of $4.0 \mathrm{~mm}$ diameter, an auxiliary electrode of carbon and a $\mathrm{Ag} / \mathrm{AgCl}$ electrode as reference electrode. $\mathrm{CV}$ measurements were carried out within a potential window of $[-0.90 \mathrm{~V} ;+0.50 \mathrm{~V}]$, at a scan rate of $50 \mathrm{mV}^{-s^{-1}}$ in PBS solution ( $\mathrm{pH}$ 7.4). For each test, the system was stable after a series of 30 continuous cycles.

\section{RESUlTS}

\section{A. CoAl-LDH Structure}

The powder XRD pattern of CoAl LDH, shown in Fig. 1a, displays the characteristic diffraction peaks $(003,006,012$, 110 and 113) of pure CoAl-LDH compounds [47], and is very similar to the XRD pattern already reported in the case of CoAl LDH containing nitrate as interlayer anion [48]. All the diffraction peaks suggest a rhombohedral structure for $\mathrm{CoAl}$ $\mathrm{LDH}$, with refined lattice parameters of $a=b=0.3067 \mathrm{~nm}$ and $c=2.2646 \mathrm{~nm}$, which are consistent with those previously published in the case of CoAl-LDH materials [47]. The sharp and symmetric features of the diffraction peaks show that CoAl-LDH is highly crystallized, having a three-dimensional order.

FTIR spectrum of CoAl-LDH shown in Fig. $1 b$ reveals the presence of four significant bands. Vibrations at $550 \mathrm{~cm}^{-1}$, $569 \mathrm{~cm}^{-1}$ and $773 \mathrm{~cm}^{-1}$ can be assigned to metal-oxide (Co and Al-O bonds) and metal-hydroxyl vibration modes, respectively. Bands observed at $1350 \mathrm{~cm}^{-1}$ and $1598 \mathrm{~cm}^{-1}$ are assigned to the symmetric stretching of carbonate $\mathrm{CO}_{3}^{-2}$ anions, coming from $\mathrm{CO}_{2}$ molecules physisorbed onto the surface [49], [50]. The presence of carbonate anions is also responsible for the weak shoulder centered at $3000 \mathrm{~cm}^{-1}$, due to $\mathrm{CO}_{3}^{2-}-\mathrm{H}_{2} \mathrm{O}$ bridging mode [51]. At last, at higher wavenumber, the broad band centered at $3373 \mathrm{~cm}^{-1}$ corresponds to the stretching modes of hydroxyl groups, revealing the presence of hydrogen-bonded interlayer water molecules, usually observed around $3300 \mathrm{~cm}^{-1}$ [49]. Other modes are also probably overlapped, such as the mode corresponding to the interaction of $\mathrm{Cl}^{-}$or $\mathrm{SO}_{4}^{2-}$ anions with water around $3000 \mathrm{~cm}^{-1}$.

Raman spectroscopy was carried out for complementary information. As shown in Fig. 1c, the Raman spectrum reveals bands at $471 \mathrm{~cm}^{-1}, 518 \mathrm{~cm}^{-1}$ and $611 \mathrm{~cm}^{-1}$ assigned to the $\nu_{2}$ mode of $\mathrm{SO}_{4}^{2-}$ anions [52] and hydroxyl groups interacting with Al. The vibration mode observed at $676 \mathrm{~cm}^{-1}$ is due to $\mathrm{CO}_{3}^{2-}$ ions, intercalated into the interlayer region [50].

Finally, all previous vibrational modes, expected in the case of such kind of compound, confirm the chemical CoAl-LDH composition.

\section{B. Morphology of CoAl-LDH Planar Films}

The surface morphology of AuSPEs was studied by AFM before and after CoAl-LDH deposition from a solution at $2.50 \mathrm{mg} \cdot \mathrm{mL}^{-1}$ (Fig. 2a and b). Topography images obtained in tapping mode show that the surface of the commercial working electrode is highly rough (rms about $500 \mathrm{~nm}$ ). Its coating by LDH film does not affect significantly its topography, surface roughness being in the same range. Such values cannot confirm any effective transfer of matter on the surface, since the AuSPE roughness prevents the distinction of the deposited LDH film. In order to confirm the success of the surface modification by the process described above, an AFM study was achieved using mica substrate under the same conditions. Indeed, freshly cleaved mica surface presents a very flat surface, particularly well-adapted to AFM characterization, enabling to monitor any significant surface modification in terms of surface organization and/or roughness. Before deposition of LDH, mica was imaged. As shown in Fig. 2c, untreated mica surface systematically cleaved in order to ensure a clean surface, and exhibits an atomic scale roughness of $0.3 \mathrm{~nm}$.

Fig. $2 \mathrm{~d}$ presents the topographic image of a CoAl film obtained by deposition on mica of a LDH solution at 


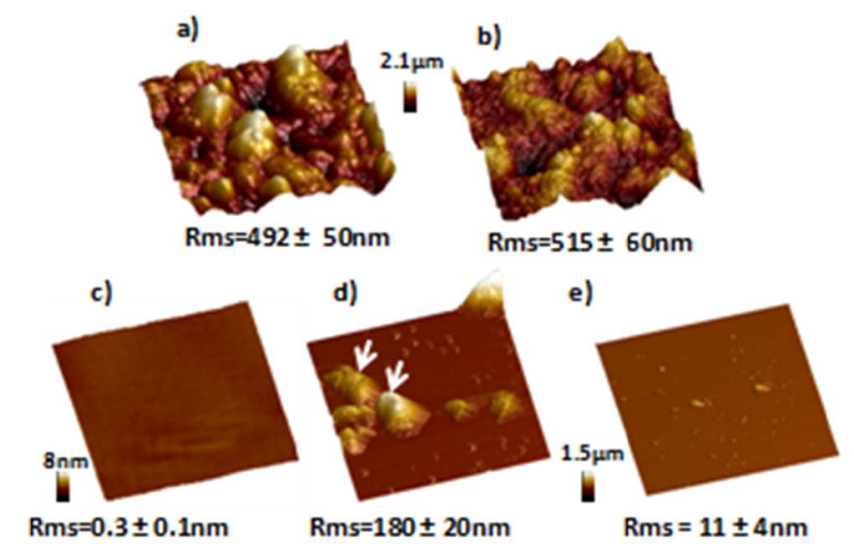

Fig. 2. 3D topographic (or height) AFM images $(20 \mu \mathrm{m} \times 20 \mu \mathrm{m})$ in tapping mode of a) nude AuSPE surface; b) AuSPE covered with a film of CoAl $\mathrm{LDH}$ (obtained from a solution at $2.5 \mathrm{mg} / \mathrm{ml}$ ); c) nude freshly cleaved mica; d) freshly cleaved mica covered with a film of CoAl LDH (same conditions as in b); and e) same sample as in d) after rinsing with ultrapure water.

$2.5 \mathrm{mg} \cdot \mathrm{mL}^{-1}$. The obtained surface is covered by many huge aggregates with a high averagesurface roughness of about $180 \mathrm{~nm}$, and presents traces of a particular organization possibly due to crystallization (indicated by arrows in Fig. 2d).

In order to eliminate those huge aggregates, an ultrapure water rinsing step was tested and a scratching operation using AFM tip in contact mode [53] was carried out on different areas of $\mathrm{LDH}$ films to ensure the coverage of the surface. All non-bonded and only adsorbed LDH particles are removed after the rinsing step (Fig. 2e). The deposited LDH film becomes tidier and the average surface roughness decreasessignificantly to less than $11 \mathrm{~nm}$. In order to obtain more details on the surface organization after this rinsing step, $2 \mathrm{D}$ zoom-in height images $(10 \mu \mathrm{m} \times 10 \mu \mathrm{m})$ were made. As shown in Fig. 3a, LDH film becomes more organized on mica and aggregates onto the surface are reduced by the rinsing step. Most parts of the surface appear to be flat and smooth presenting layers with different height levels (differently colored areas) and some small aggregates (lightest colored areas). The corresponding average surface roughness $(5-11 \mathrm{~nm})$ is clearly above the roughness of freshly cleaved mica suggesting the presence of a LDH film. The zoom-in image (2 $\mu \mathrm{m}$ $\times 2 \mu \mathrm{m}$, Fig. 3b) performed in the selected zone indicated by a dashed square in Fig. 3a, showsLDH layers. The uniformity of the contrast observed in the corresponding phase images (Fig. 3d) indicates the homogenous coverage of the surface by a monophasic material.

Height profile cross sections performed on height images (Fig. 3c) confirm the deposition of ultrathin layers of LDH. The height of a step is estimated to $1-5 \mathrm{~nm}$, whereas the global thickness is estimated to about $25 \mathrm{~nm}$ after scratching. In order to obtain homogenous, less rough and thinner CoAl-LDH films with a reduction of aggregate number and size, we studied the influence of lower CoAl-LDH concentrations, ranging from 0.50 to $2.50 \mathrm{mg} \cdot \mathrm{mL}^{-1}$, on the quality of LDH coating.

The decrease of the LDH concentration enhances significantly the quality of the deposited LDH films that become
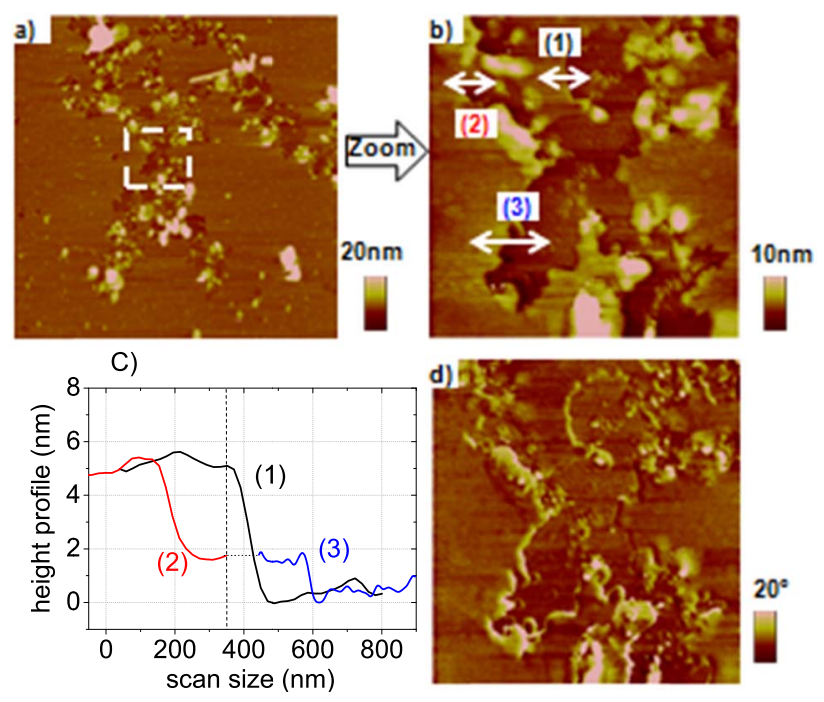

Fig. 3. AFM images in tapping mode of a CoAl-LDH film $\left(\mathrm{C}_{\mathrm{LDH}}=\right.$ $\left.2.5 \mathrm{mg} \cdot \mathrm{mL}^{-1}\right)$ : (a) height image $(10 \mu \mathrm{m} \times 10 \mu \mathrm{m})$; (b) height image of the selected area indicated by a square on the previous image $(2 \mu \mathrm{m} \times 2$ $\mu \mathrm{m}$ ); (c) height profiles extracted from cross-sections indicated in (b) and (d) corresponding phase image of (b).

a)
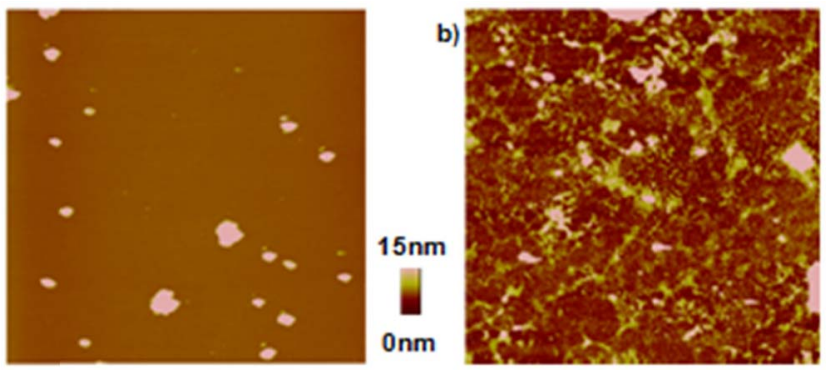

Fig. 4. AFM height images in tapping mode $(5 \mu \mathrm{m} \times 5 \mu \mathrm{m})$ of a CoAlLDH film $\left(\mathrm{C}_{\mathrm{LDH}}=0.75 \mathrm{mg} \cdot \mathrm{mL}^{-1}\right)$ before (a) and after (b) tyrosinase film deposition.

more homogenous, as shown by height and phase images of a LDH film obtained from a solution at $0.75 \mathrm{mg} \cdot \mathrm{mL}^{-1}$ (Fig. 4a). At the lowest concentration $\left(0.50 \mathrm{mg} \cdot \mathrm{mL}^{-1}\right)$, surfaces are not homogenously covered, LDH being even absent in some areas (data not shown). At the same time, the roughness decreases regularly from $11 \mathrm{~nm}$ (at a concentration of $2.50 \mathrm{mg} \cdot \mathrm{mL}^{-1}$ ) to a lower value of 3-5 nm (at a concentration of $0.50-0.75 \mathrm{mg} \cdot \mathrm{mL}^{-1}$ ). The scratching operation performed on those last films reveals variable thicknesses. By contrast, in the case of samples obtained from solutions at $0.75 \mathrm{mg} \cdot \mathrm{mL}^{-1}$, the thickness is more regular and estimated to $10 \mathrm{~nm}$ after rinsing.

Taking into account that a regular coverage is more suitable for the enzyme binding in terms of orientation and accessibility, and that LDH surfaces obtained with a solution at $0.75 \mathrm{mg} \cdot \mathrm{mL}^{-1}$ are well characterized in terms of roughness, thickness and homogeneity, we considered this concentration as the optimal one for the following tyrosinase binding.

AFM was also used at this step to check the presence of the enzyme after the reticulation step. Fig. $4 \mathrm{~b}$ shows an 


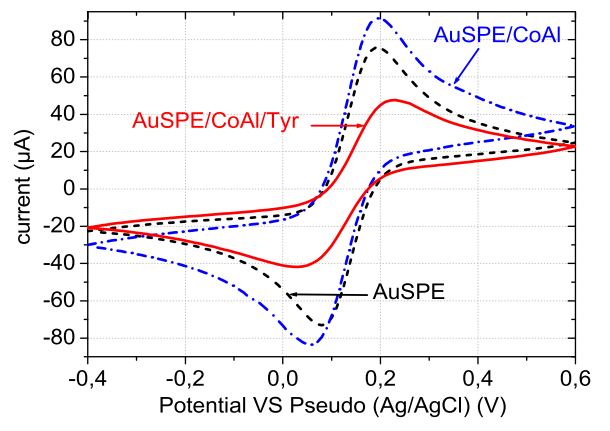

Fig. 5. Cyclic voltammograms of nude AuSPE, AuSPE modified by the deposition of the CoAl-LDH film $\left(\mathrm{C}_{\mathrm{LDH}}=0.75 \mathrm{mg} \cdot \mathrm{mL}^{-1}\right)$ and AuSPE modified by the immobilization of tyrosinase (Tyr) on the CoAl-LDH film. Experiments were carried out in PBS containing ferri-ferrocyanide couple (3mM) at room temperature.

AFM height image suggesting the presence of tyrosinase molecules more or less organized at the surface. Finally the same procedure was followed to functionalize AuSPE surfaces.

\section{Impact of the Different (AuSPE / CoAl-LDH / Tyrosinase) Functionnalization Steps on the Voltammetric Response}

In this section, electrochemical properties resulting from the different AuSPE modification steps were analyzed by cyclic voltammetry (CV) until the complete characterization of the elaborated biosensor.Fe $(\mathrm{CN})_{6}^{-3 /-4}$ redox couple was used here as electrolyte support to amplify the effect of each functionalization step on current. The chosen potential window is larger than the appropriate one for this redox couple (from $-0.40 \mathrm{~V}$ to $0.60 \mathrm{~V}$ ) [54].

Fig. 5 shows the $\mathrm{CV}$ responses of the nude AuSPE taken as reference, the AuSPE modified first by the deposition of the film of CoAl LDH, and then by the immobilization of tyrosinase on the $\mathrm{LDH}$ film.

Voltammetric response of nude AuSPE is characterized by redox peaks of the $\mathrm{Fe}(\mathrm{CN})_{6}^{-3 /-4}$ couple at potentials of $+0.19 \mathrm{~V}$ and $+0.08 \mathrm{~V}$, these redox reactions being reversible (Fig. 5). The deposition of LDH does not change the overall shape of the current-potential response, but increases the intensity of both peaks, in agreement with electroactive properties of Co ions, already reported [32].

On the contrary, the presence of the tyrosinase layer deposited on LDH film induces important changes in the $\mathrm{CV}$ response. First, peaks are enlarged and shifted: oxidation peak is observed at $0.23 \mathrm{~V}$, whereas the reduction one appears at $0.03 \mathrm{~V}$. Secondly, the intensity of these peaks is clearly reduced as compared to previous ones. Such changes are consistent with the presence of the enzyme on the electrode surface [55], [56]. At last, the properties of such hybrid system are reproducible and reversible, always stable after 50 cycles (data not shown).

\section{Detection by CV of Polyphenols Using the (CoAl-LDH/ Tyrosinase) Coated AuSPE}

The biosensor made by the AuSPE/CoAl-LDH film/ tyrosinase association was immersed in PBS and successive
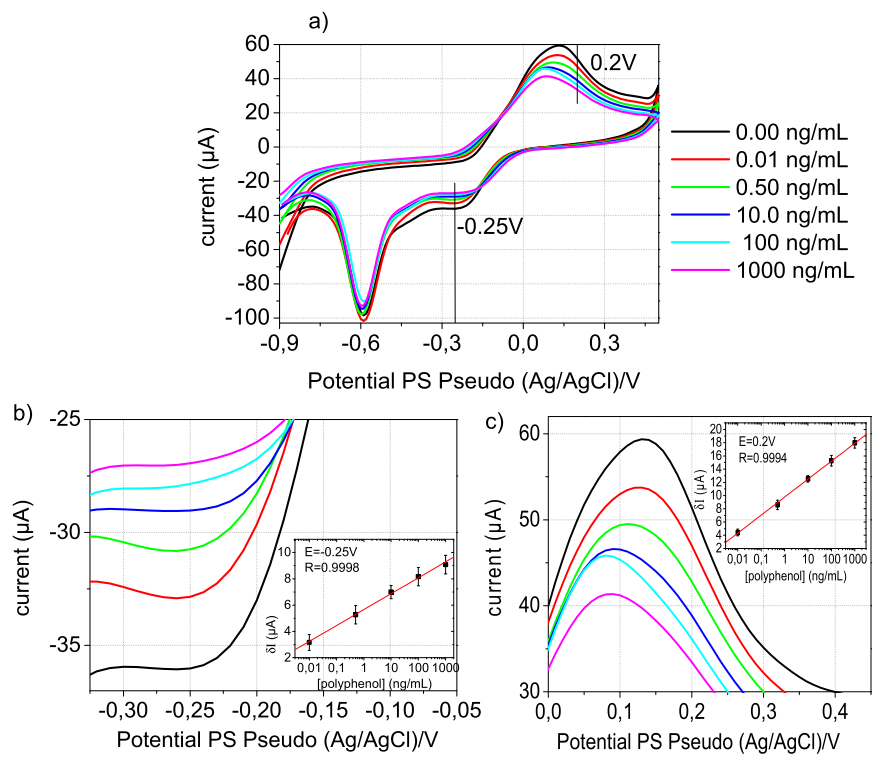

Fig. 6. Cyclic voltammograms of the AuSPE modified by the immobilization of tyrosinase on the CoAl-LDH film in the presence of increasing concentrations of polyphenols from 0 to $1000 \mathrm{ng} \cdot \mathrm{mL}^{-1}$ in PBS at room temperature (a); (b) and (c) selected areas corresponding to the reduction peak at $-0.25 \mathrm{~V}$ and the oxidation one at $+0.13 \mathrm{~V}$. Corresponding calibration straights at $-0.25 \mathrm{~V}$ and $+0.13 \mathrm{~V}$ are added.

polyphenol amounts corresponding to final concentrations from 0.01 to $2000.00 \mathrm{ng} \cdot \mathrm{mL}^{-1}$ were injected into the cell. The corresponding $\mathrm{CV}$ curves were recorded within the $[-0.90 \mathrm{~V} ;+0.50 \mathrm{~V}]$ potential range. Fig. 6a shows voltammograms typical of those obtained for three different biosensors built under the same experimental conditions.

In the absence of polyphenols, the $\mathrm{CV}$ response of the system is characterized by the presence of two intense peaks at $-0.59 \mathrm{~V}$ and $+0.13 \mathrm{~V}$ and a shoulder at $-0.25 \mathrm{~V}$. Peaks at $+0.13 \mathrm{~V}$ and $-0.25 \mathrm{~V}$ can be assigned to oxido-reduction processes involving cobalt contained in $\mathrm{LDH}$, as previously mentioned [26]. Taking into account the high intensity of the peak at $-0.59 \mathrm{~V}$, it could be due to processes involving components of PBS.

In the presence of increasing concentrations of polyphenols, the peak at $+0.13 \mathrm{~V}$ is progressively shifted to lower potential values. This effect, already observed in the case of tyrosinasebased biosensors using carbon nanotubes/cobalt/phtalocyanine architectures as matrix, is assigned to the antioxidant properties of polyphenols [26]. Moreover, the intensity of this peak decreases, although electrochemical oxidation of catechins (main polyphenols of tea) occurs at a close potential value around $+0.20 \mathrm{~V}$ [57]. This result is in agreement with a previous work [26], can be explained by the presence of catechins who reduce or hide the peaks assigned to cobalt.

The peak at $-0.25 \mathrm{~V}$ is stable in potential, but a regular decrease of its amplitude is observed in the presence of increasing concentrations of polyphenols. At this potential value, two mechanisms can coexist: already mentioned oxido-reduction processes involving cobalt, and electrochemical reduction of products enzymatically formed by tyrosinase [26], [58]-[60], the global current intensity including the 


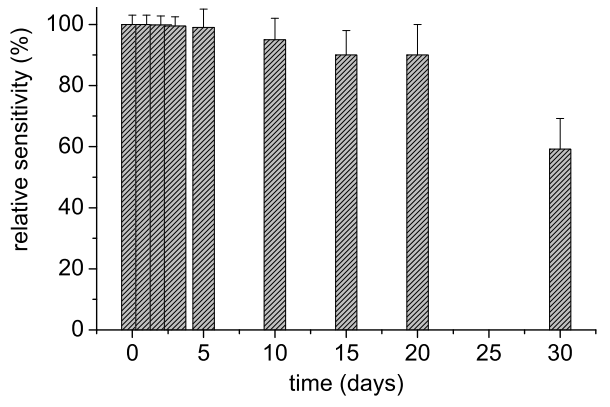

Fig. 7. Study of the life time of the AuSPE/CoAlSO 4 /tyrosinase biosensor stored in PBS (sensitivity based on measurements at a potential of $0.20 \mathrm{~V}$ ).

two processes. At both potential values $(+0.13 \mathrm{~V}$ and $-0.25 \mathrm{~V})$, the saturation is observed at polyphenol concentration above 1000 ng. $\mathrm{mL}^{-1}$ (data not shown). Finally, as compared to other ones, the peak at $-0.59 \mathrm{~V}$ does not change regularly with the polyphenol concentration, which would be in agreement with the involvement of buffer solution.

Taking into account the amplitude of current variations observed in the presence of increasing polyphenol concentrations, we focused on potential values at $-0.25 \mathrm{~V}$ and $+0.20 \mathrm{~V}$, characterized by highest current variation, giving thus the best sensitivity of detection. Fig. $6 \mathrm{~b}$ and $6 \mathrm{c}$ show more precisely the responses of one of the three biosensors (representative of results obtained in each case) in terms of measured current $\left(I_{m}\right)$ at these two potential values, and the corresponding calibration curves giving the absolute value of the current variation $\delta \mathrm{I}=\left|I_{m}-I_{0}\right|$, where $I_{0}$ is the current measured in the absence of polyphenol, versus polyphenol concentrations, in logarithmic scale. These curves are linear within the range 0-1000 ng. $\mathrm{mL}^{-1}$ of polyphenol concentration. In the case of the oxidation peak at $+0.20 \mathrm{~V}$, the linear response is characterized by a maximal value of $\delta \mathrm{I}$ around $20 \mu \mathrm{A}$, with a slope of $2.74 \mu \mathrm{A} / \mathrm{ng} \cdot \mathrm{mL}^{-1}(R=0.9994)$. In the case of the reduction peak, corresponding values are $9 \mu \mathrm{A}$ and $1.20 \mu \mathrm{A} / \mathrm{ng} \cdot \mathrm{mL}^{-1}(R=0.9998)$, respectively. The limits of detection (LOD) are estimated by the standard deviation method around $0.33 \mathrm{pg} . \mathrm{mL}^{-1}$ and $0.03 \mathrm{pg} . \mathrm{mL}^{-1}$ for oxidation and reduction respectively.

Stability and the repeatability of measurements were studied as follows: one test (on the complete concentration range) per day for five consecutive days, then one test every 5 days, for 25 to 30 days. Fig. 7 shows the relative sensitivity (ratio between the measured sensitivity and the initial one as reference, expressed in percentage) with time. This figure shows that our biosensor is stable after 20 days, since it keeps $90 \%$ of the sensitivity of day 1 . At last, after each measurement series, biosensors were stored in PBS at $4^{\circ} \mathrm{C}$.

\section{Discussion}

Theoretically, no functionnalization is needed for the electrochemical detection of polyphenols. It has been shown that the presence of phenols can be detected by their electrochemical oxidation at the surface of platinum, gold or platinum/gold electrodes in acid medium. However, a deposit assigned to polymerization fouls the electrode surface [61]. Functionnalization of this surface is thus necessary, either by a pure chemical way using for instance LDH/cobalt-phtalocyanine ultrathin films [42] or pyrolytic deposited graphite [62], or by an enzymatic one. In this last case, tyrosinase is one of the most used enzymes.

The mechanism of tyrosinase-based biosensors has been already described [26], [27], [63]. It is based on three steps: first polyphenols are enzymatically oxidized in o-diphenols; secondly, these compounds are oxidized by tyrosinase in oquinones; at last, o-quinones are electrochemically reduced at the active surface, as schematized by the following equation where Tyr represents tyrosinase:

polyphenol $\stackrel{T y r}{\longrightarrow} \ldots \stackrel{\text { Tyr }}{\longrightarrow}$ o-quinone $\stackrel{\text { Red. }}{\longrightarrow}$ o-diphenol However, LDH can also be involved in the oxidation of polyphenols via the following mechanism [32]:

$$
\begin{aligned}
& L D H-\mathrm{Co}^{(I I)}+\mathrm{OH}_{\text {solution }}^{-} \rightarrow \mathrm{LDH}\left(\mathrm{OH}^{-}\right)-\mathrm{Co}^{(I I I)}+e^{-} \\
& \quad L D H\left(O H^{-}\right)-\mathrm{Co}^{(I I I)}+\text { polyphenol } \rightarrow \mathrm{LDH}-\mathrm{Co}^{(I I)} \\
& +o-\text { quinone }+\mathrm{OH}^{-}
\end{aligned}
$$

In this context, most of these biosensors enable to detect polyphenols indirectly, by following the current corresponding to the reduction peak, this solution being usually preferred in order to avoid interferences. However, contrary to our case, the reduction current increases proportionally to the polyphenol concentration [27], [63]. An alternative solution remains to use the oxidation signal due to oxidized compounds generated by tyrosinase.

In our case, the presence of the reduction peak confirms first that the experimental procedure used to immobilize tyrosinase respects enzyme conformation and activity. Moreover, our results shows that this biosensor based on hybrid LDH-tyrosinase material enables to detect the presence of polyphenols by following two different signals at the same time, reduction and oxidation ones, (at $-0.25 \mathrm{~V}$ and $+0.20 \mathrm{~V}$, respectively), leading to a more reliable sensor. However, the amplitude of both currents decreases when polyphenol concentrations increase, which could be due to the superposition of contradictory processes. In particular at $-0.25 \mathrm{~V}$, the global intensity decrease suggests that the signal due to the reduction of enzymatically formed o-quinones would be too weak to prevail on cobalt process. Moreover, it has been shown that several polyphenols may act as inhibitors of tyrosinase, thus playing a role in the current intensity [64].

At last, concerning its performances, in both oxidation and reduction modes, the designed biosensor is highly sensitive $\left(2.74 \mu \mathrm{A} / \mathrm{ng} \cdot \mathrm{mL}^{-1}\right.$ and $\left.1.20 \mu \mathrm{A} / \mathrm{ng} \cdot \mathrm{mL}^{-1}\right)$ for a very large linear dynamic range (from 0.01 to $1000 \mathrm{ng} \cdot \mathrm{mL}^{-1}$ ). LODs are also estimated at 0.33 pg. $\mathrm{mL}^{-1}$ and 0.04 pg. $\mathrm{mL}^{-1}$ respectively. These biosensor features correspond to averages, since obtained with a mixture of polyphenols extracted from green tea. Indeed, biosensor efficiency should vary with the nature of polyphenols, as described in literature [17]-[19], [22], [23], [30], [40], [58], [63]-[65]. However, it is possible to determine a mean molecular mass of polyphenols at $415 \mathrm{~g} \cdot \mathrm{mol}^{-1}$, by taking into account the molar mass of each compound present in the mixture and its relative 
percentage determined from previous analyses [44]. Based on this estimation, we obtain a linear range of 0-2.4 $\mu \mathrm{M}$, leading to the conclusion that it is particularly well-adapted to the detection of low concentrations (typical limits of detection and linear ranges usually range from $\mathrm{nM}$ to hundreds of $\mu \mathrm{M}$ in the case of tyrosinase-based biosensors [16]-[18], [20]-[25], [27], [28], [63], [65]. In the context of tea polyphenol detection, our maximal concentrations for a linear biosensor response are in agreement with those obtained in tea decoctions, which are around 2-5 $\mu \mathrm{M}$ [17].

Taking into account the previous estimated molar mass and the sensitive surface of our biosensor $\left(12.6 \mathrm{~mm}^{2}\right)$, it is also possible to estimate its sensitivity. In the oxidation-based mode, the sensitivity of $2.74 \mu \mathrm{A} / \mathrm{ng} \cdot \mathrm{mL}^{-1}$ is equivalent to $1140 \mathrm{~A} \cdot \mathrm{M}^{-1}$ or $9000 \mathrm{~A} \cdot \mathrm{M}^{-1} \cdot \mathrm{cm}^{-2}$. In the reduction-based mode, the same estimation gives a sensitivity of $1.20 \mu \mathrm{A} / \mathrm{ng} \cdot \mathrm{mL}^{-1}$ equivalent to $498 \mathrm{~A} \cdot \mathrm{M}^{-1}$ or $3952 \mathrm{~A} . \mathrm{M}^{-1} \cdot \mathrm{cm}^{-2}$. These values are high as compared to others previously reported for tyrosinase-based systems [16]-[18], [23], [24], [28], [63], [66] which is useful for the comfort of detection and its quantification.

\section{CONCLUSiON}

In this study, we describe the efficient immobilization of tyrosinase enzyme on CoAl-LDH nanomaterial (never used until now for tyrosinase immobilization) previously deposited at the surface of an electrode, to detect polyphenols. Various techniques of characterization enabled us to check the efficiency of the CoAl-LDH synthesis and to confirm its highly crystallized state. Then, AuSPE were treated and functionalized with a simple, efficient and inexpensive procedure which consists in the deposition of an ultra-thin layer of CoAl-LDH and the immobilization of tyrosinase by SAM processes. Thanks to AFM technique, the homogeneity of LDH films was optimized by studying the effect on their thickness and roughness of decreasing LDH concentrations.

Finally, the electrochemical polyphenol biosensor developed in this work proves to be competitive, reliable (thanks to the two modes of polyphenol detection), reusable with a good repeatability and adapted to natural extracts in liquid media. In particular its characteristics suggest that this biosensor is well-adapted to detection of polyphenols in other contexts that food-processing, such as environmental or medical ones, where it is necessary to detect traces.

\section{ACKNOWLEDGMENT}

The authors thank Gérard Couturier, Denise Mondieig and Philippe Négrier (Laboratoire Ondes et Matière d'Aquitaine, LOMA, Université de Bordeaux, UMR CNRS 5798, Talence, France) and the NSI platform of LOMA (CPER COLA2) for helpful discussions and technical support.

\section{REFERENCES}

[1] J. M. M. Andrade and D. Fasolo, "Polyphenol antioxidants from natural sources and contribution to health promotion," in Polyphenols Human Health Disease, 1st ed. vol. 20. Amsterdam, The Netherland, Elsevier, 2013, pp. 253-265.
[2] K. S. Bhullar and H. P. V. Rupasinghe, "Antioxidant and cytoprotective properties of partridgeberry polyphenols," Food Chem. J., vol. 168, pp. 595-605, Feb. 2015.

[3] P. M. Kris-Etherton et al., "Bioactive compounds in foods: Their role in the prevention of cardiovascular disease and cancer," Amer. J. Med., vol. 113, no. 9, pp. 71-88, 2002.

[4] A. Scalbert, C. Morand, C. Manach, and C. Rémésy, "Absorption and metabolism of polyphenols in the gut and impact on health," Biomed. Pharmacotherapy, vol. 56, no. 6, pp. 276-282, 2002.

[5] Q. V. Vuonga, S. Hiruna, P. A. Phillips, T. L. K. Chuena, M. C. Bowyer, and C. D. Goldsmitha, "Fruit-derived phenolic compounds and pancreatic cancer: Perspectives from Australian native fruits," J. Ethnopharmacol., vol. 152, no. 2, pp. 227-242, 2014.

[6] L. Campanella, A. Bonanni, and M. Tomassetti, "Determination of the antioxidant capacity of samples of different types of tea, or of beverages based on tea or other herbal products, using a superoxide dismutase biosensor," J. Pharmaceutical Biomed. Anal., vol. 32, no. 4, pp. 725-736, 2003.

[7] S. A. S. S. Gomes and M. J. F. Rebelo, "A new laccase biosensor for polyphenols determination," Sensors, vol. 3, no. 6, pp. 166-175, 2003.

[8] P. Ibarra-Escutia, J. J. Gomez, C. Calas-Blanchard, J. L. Marty, and M. T. Ramirez-Silva, "Amperometric biosensor based on a high resolution photopolymer deposited onto a screen-printed electrode for phenolic compounds monitoring in tea infusions," Talanta, vol. 81, no. 4, pp. 1636-1642, 2010.

[9] S. Imabayashi, Y.-T. Kong, and M. Watanabe, "Amperometric biosensor for polyphenol based on horseradish peroxidase immobilized on gold electrodes," Electroanalysis, vol. 13, no. 5, pp. 408-412, 2001.

[10] L. D. Mello, A. A. Alves, V. V. Macedo, and L. T. Kubota, "Peroxidasebased biosensor as a tool for a fast evaluation of antioxidant capacity of tea," Food Chem., vol. 92, no. 3, pp. 515-519, 2005.

[11] S. Korkut, B. Keskinler, and E. Erhan, "An amperometric biosensor based on multiwalled carbon nanotube-poly (pyrrole)-horseradish peroxidase nanobiocomposite film for determination of phenol derivatives," Talanta, vol. 76, no. 5, pp. 1147-1152, 2008.

[12] G. M. Casanola-Martin et al., "Tyrosinase enzyme: 1 . An overview on a pharmacological target," Current Topics Med. Chem., vol. 14, no. 12, pp. 1494-1501, 2014.

[13] S. Halaouli, M. Asther, J.-C. Sigoillot, M. Hamdi, and A. Lomascolo, "Fungal tyrosinases: New prospects in molecular characteristics, bioengineering and biotechnological applications," J. Appl. Microbiol., vol. 100, no. 2, pp. 219-232, 2006.

[14] K. S. Abhijith, P. V. S. Kumar, M. A. Kumar, and M. S. Thakur, "Immobilised tyrosinase-based biosensor for the detection of tea polyphenols," Anal. Bioanal. Chem., vol. 389, nos. 7-8, pp. 2227-2234, 2007.

[15] R. Han, L. Cui, S. Ai, H. Yin, X. Liu, and Y. Qiu, "Amperometric biosensor based on tyrosinase immobilized in hydrotalcite-like compounds film for the determination of polyphenols," J. Solid State Electrochem., vol. 16, no. 2, pp. 449-456, 2012.

[16] S. Nadifiyine, C. C. Blanchard, A. Amine, and J. L. Marty, "Tyrosinase biosensor used for the determination of catechin derivatives in tea: Correlation with HPLC/DAD method," Food Nutrition Sci., vol. 4, no. 1, p. 108, 2013.

[17] M. Cortina-Puig, X. Muñoz-Berbel, C. Calas-Blanchard, and J. L. Marty, "Diazonium-functionalized tyrosinase-based biosensor for the detection of tea polyphenols," Microchim. Acta, vol. 171, nos. 1-2, pp. 187-193, 2010.

[18] B. Wang, J. Zhang, and S. Dong, "Silica sol-gel composite film as an encapsulation matrix for the construction of an amperometric tyrosinasebased biosensor," Biosensors Bioelectron., vol. 15, no. 7, pp. 397-402, 2000.

[19] H. Notsu, T. Tatsuma, and A. Fujishima, "Tyrosinase-modified borondoped diamond electrodes for the determination of phenol derivatives," J. Electroanal. Chem., vol. 523, no. 1, pp. 86-92, 2002.

[20] N. Zehani et al., "Highly sensitive electrochemical biosensor for bisphenol A detection based on a diazonium-functionalized boron-doped diamond electrode modified with a multi-walled carbon nanotube-tyrosinase hybrid film," Biosensors Bioelectron., vol. 74, pp. 830-835, Dec. 2015.

[21] S. Tembe, S. Inamdar, S. Haram, M. Karve, and S. F. D'Souza, "Electrochemical biosensor for catechol using agarose-guar gum entrapped tyrosinase," J. Biotechnol., vol. 128, no. 1, pp. 80-85, 2007.

[22] V. C. Sanz, M. L. Mena, A. González-Cortés, P. Yanez-Sedeno, and J. M. Pingarrón, "Development of a tyrosinase biosensor based on gold nanoparticles-modified glassy carbon electrodes: Application to the measurement of a bioelectrochemical polyphenols index in wines," Anal. Chim. Acta, vol. 528, no. 1, pp. 1-8, 2005. 
[23] S. Wang, Y. Tan, D. Zhao, and G. Liu, "Amperometric tyrosinase biosensor basedonFe $\mathrm{O}_{4}$ nanoparticles-chitosannanocomposites," Biosensors Bioelectron., vol. 23 , no. 1, pp. 1781-1787, 2008.

[24] J. Zhang, J. Lei, Y. Liu, J. Zhao, and H. Ju, "Highly sensitive amperometric biosensors for phenols based on polyaniline-ionic liquidcarbon nanofiber composite," Biosensors Bioelectron., vol. 24, no. 7, pp. 1858-1863, 2009.

[25] H. Yin, Y. Zhou, J. Xu, S. Ai, L. Cui, and L. Zhu, "Amperometric biosensor based on tyrosinase immobilized onto multiwalled carbon nanotubes-cobalt phthalocyanine-silk fibroin film and its application to determine bisphenol A," Anal. Chim. Acta, vol. 659, no. 1, pp. 144-150, 2010.

[26] I. M. Apetrei, M. L. Rodriguez-Mendez, C. Apetrei, and J. A. de Saja, "Enzyme sensor based on carbon nanotubes/cobalt (II) phthalocyanine and tyrosinase used in pharmaceutical analysis," Sens. Actuators B, Chem., vol. 177, pp. 138-144, Feb. 2013.

[27] I. M. Apetrei and C. Apetrei, "The biocomposite screen-printed biosensor based on immobilization of tyrosinase onto the carboxyl functionalised carbon nanotube for assaying tyramine in fish products," J. Food Eng., vol. 149, pp. 1-8, Mar. 2015 .

[28] J. Kochana et al., "Tyrosinase-based biosensor for determination of bisphenol A in a flow-batch system," Talanta, vol. 144, pp. 163-170, Nov. 2015.

[29] N. Gupta, S. Sharma, I. A. Mir, and D. Kumar, "Advances in sensors based on conducting polymers," J. Sci. Ind. Res., vol. 65, no. 7, pp. 549-557, 2006.

[30] R. A. Sheldon, "Enzyme immobilization: The quest for optimum performance," Adv. Synth., Catal., vol. 349, nos. 8-9, pp. 1289-1307, 2007.

[31] C. Mousty and V. Prévot, "Hybrid and biohybrid layered double hydroxides for electrochemical analysis," Anal. Bioanal. Chem., vol. 405 , no. 11 , pp. 3513-3523, 2013

[32] D. Tonelli, E. Scavetta, and M. Giorgetti, "Layered-double-hydroxidemodified electrodes: Electroanalytical applications," Anal. Bioanal. Chem., vol. 405, nos. 2-3, pp. 603-614, 2013.

[33] D. Shan, S. Cosnier, and C. Mousty, "Layered double hydroxides: An attractives material for electrochemical biosensor design," Anal. Chem., vol. 75, no. 5, pp. 3872-3879, 2003.

[34] S. Aisawa, S. Takahashi, and E. Narita, "Direct intercalation of amino acids into layered double hydroxides by coprecipitation," J. Solid State Chem., vol. 162, no. 1, pp. 52-62, 2001.

[35] Z. M. Baccar, D. Caballero, R. Eritja, and A. Errachid, "Development of an impedimetric DNA-biosensor based on layered double hydroxide for the detection of long ssDNA sequences," Electrochim. Acta, vol. 74, pp. 123-129, Jul. 2012.

[36] Z. M. Baccar, D. Caballero, N. Zine, and N. A. J.-R. Errachid, "Development of Urease/LDHs nanohybrid materials for the urea detection: synthesis, analytical and catalytical characterizations," Sensors Lett., vol. 7, pp. 676-682, Jul. 2009.

[37] Z. M. Baccar, S. Hidouri, N. El Bari, N. Jaffrezic-Renault, A. Errachid, and N. Zine, "Stable immobilization of anti-beta casein antibody onto layered double hydroxides materials for biosensor applications," Sensors Lett., vol. 7, no. 5, pp. 647-655, 2009.

[38] S. Hidouri, Z. M. Baccar, H. Abdelmelek, T. Noguer, J. L. Marty, and M. Campás, "Structural and functional characterisation of a biohybrid material based on acetylcholinesterase and layered double hydroxides," Talanta, vol. 85, no. 4, pp. 1882-1887, 2011.

[39] M. Temani, Z. M. Baccar, and H. B. Mansour, "Structural and functional characterisation of a biohybrid material based on acetylcholinesterase and layered double hydroxides," Microelectron. Eng., vol. 126, no. 4 , pp. 165-168, 2014.

[40] E. Han, D. Shan, H. Xue, and S. Cosnier, "Hybrid material based on chitosan and layered double hydroxides: Characterization and application to the design of amperometric phenol biosensor," Biomacromolecules, vol. 8, no. 3, pp. 971-975, 2007.

[41] J. R. Jara, F. Solano, J. C. Garcia-Borron, P. Aroca, and J. A. Lozano, "Regulation of mammalian melanogenesis II: The role of metal cations," Biochim. Biophys. Acta, vol. 1035, no. 3, pp. 276-285, 1990.

[42] J. Han, X. Xu, X. Rao, M. Wei, D. G. Evans, and X. Duan, "Layerby-layer assembly of layered double hydroxide/cobalt phthalocyanine ultrathin film and its application for sensors," J. Mater. Chem., vol. 21, no. 7, pp. 2126-2130, 2011.

[43] M. Trojanowicz, "Impact of nanotechnology on design of advanced screen-printed electrodes for different analytical applications," Trends Anal. Chem., vol. 84, no. 7, pp. 22-47, 2016.
[44] M. Friedman, C. E. Levin, S.-H. Choi, E. Kozukue, and N. Kozukue, "HPLC analysis of catechins, theaflavins, and alkaloids in commercial teas and green tea dietary supplements: Comparison of water and $80 \%$ ethanol/water extracts," J. Food Sci., vol. 71, no. 6, pp. C328-C337, 2006.

[45] H. Xue and Z. Shen, "A highly stable biosensor for phenols prepared by immobilizing polyphenol oxidase into polyaniline-polyacrylonitrile composite matrix," Talanta, vol. 57, no. 2, pp. 289-295, 2002.

[46] L. Nony, R. Boisgard, and J. P. Aime, "Nonlinear dynamical properties of an oscillating tip-cantilever system in the tapping mode," J. Chem. Phys., vol. 111, no. 4, pp. 1615-1627, 1999.

[47] R. E. Johnsen, F. Krumeich, and P. Norby, "Structural and microstructural changes during anion exchange of CoAl layered double hydroxides: An in situ X-ray powder diffraction study," J. Appl. Crystallogr., vol. 43, no. 3, pp. 434-447, 2010 .

[48] J. C. Manayil, S. Sankaranarayanan, D. S. Bhadoria, and K. Srinivasan, "CoAl- $\mathrm{CrO}_{4}$ layered double hydroxides as selective oxidation catalysts at room temperature," Ind. Eng. Chem. Res., vol. 50, no. 23, pp. 13380-13386, 2011.

[49] S. Kannan and C. S. Swamy, "Synthesis and physicochemical characterization of cobalt aluminium hydrotalcite," J. Mater. Sci. Lett., vol. 11, no. 23 , pp. $1585-1587,1992$.

[50] A. C. Vieira, R. L. Moreira, and A. Dias, "Raman scattering and Fourier transform infrared spectroscopy of $\mathrm{Me}_{6} \mathrm{Al}_{2}(\mathrm{OH})_{16} \mathrm{Cl}_{2} \cdot 4 \mathrm{H}_{2} \mathrm{O}(\mathrm{Me}=\mathrm{Mg}$, $\mathrm{Ni}, \mathrm{Zn}, \mathrm{Co}$, and $\mathrm{Mn})$ and $\mathrm{Ca}_{2} \mathrm{Al}(\mathrm{OH})_{6} \mathrm{Cl}_{2} 2 \mathrm{H}_{2} \mathrm{O}$ hydrotalcites," J. Phys. Chem. C, vol. 113, no. 30, pp. 13358-13368, 2009.

[51] J. T. Kloprogge and R. L. Frost, "Fourier transform infrared and Raman spectroscopic study of the local structure of $\mathrm{Mg}_{-}, \mathrm{Ni}-$, and $\mathrm{Co}-$ hydrotalcites," J. Solid State Chem., vol. 146, no. 2, pp. 506-515, 1999.

[52] D. V. Radziuk and H. Möhwald, "Spectroscopic investigation of composite polymeric and monocrystalline systems with ionic conductivity," Polymers, vol. 3, no. 2, pp. 674-692, 2011.

[53] R. W. Carpick and M. Salmeron, "Scratching the surface: Fundamental investigations of tribology with atomic force microscopy," Chem. Rev., vol. 97, no. 4, pp. 1163-1194, 1997.

[54] J. E. O'Reilly, "Oxidation reduction potential of the ferroferricyanide system in buffer solutions," Biochim. Biophys. Acta, vol. 292, no. 3, pp. 509-515, 1973.

[55] R. Villalonga, P. Díez, S. Casado, E. Eguílaz, P. Yáñez-Sedeño, and J. M. Pingarrón, "Electropolymerized network of polyamidoamine dendron-coated gold nanoparticles as novel nanostructured electrode surface for biosensor construction," Analyst, vol. 137, no. 2, pp. 342-348, 2012.

[56] $\mathrm{D}$. $\mathrm{Li}$ et al., "NiCu alloy nanoparticle-loaded carbon nanofibers for phenolic biosensor applications," Sensors, vol. 15, no. 11, pp. 29419-29433, 2015.

[57] C-T. Ho, J-K. Lin, and F. Shahidi, Tea and Tea Products: Chemistry and Health-Promoting Properties. Boca Raton, Fl, USA: CRC Press, 2008.

[58] D. Shan, C. Mousty, and S. Cosnier, "Subnanomolar cyanide detection at polyphenol oxidase/clay biosensors," Anal. Chem., vol. 76, no. 1, pp. 178-183, 2004.

[59] M. S.-P. Lopez, F. Charmantray, V. Helaine, L. Hecquet, and C. Mousty, "Electrochemical detection of transketolase activity using a tyrosinase biosensor," Biosensors Bioelectron., vol. 26, no. 1, pp. 139-143, 2010.

[60] D. A. Oriero, I. O. Gyan, B. W. Bolshaw, I. F. Cheng, and D. E. Aston, "Electrospun biocatalytic hybrid silica-PVA-tyrosinase fiber mats for electrochemical detection of phenols," Microchem. J., vol. 118, pp. 166-175, Jan. 2015.

[61] P. I. Iotov and S. V. Kalcheva, "Mechanistic approach to the oxidation of phenol at a platinum/gold electrode in an acid medium," J. Electroanal. Chem., vol. 442, no. 1, pp. 19-26, 1998.

[62] J. Riedel, M. Berthold, and U. Guth, "Pyrolytic deposited graphite electrodes for voltammetric sensors: An alternative to nano structured electrodes," Sens. Actuators A, Phys., vol. 241, pp. 212-215, Apr. 2016.

[63] S. Andreescu and O. A. Sadik, "Correlation of analyte structures with biosensor responses using the detection of phenolic estrogens as a model," Anal. Chem., vol. 76, no. 3, pp. 552-560, 2004.

[64] T.-S. Chang, "An updated review of tyrosinase inhibitors," Int. J. Molecular Sci., vol. 10, no. 6, pp. 2440-2475, 2009.

[65] E. Dempsey, D. Diamond, and A. Collier, "Development of a biosensor for endocrine disrupting compounds based on tyrosinase entrapped within a poly(thionine) film, Biosensors and Bioelectronics," Biosensors Bioelectron., vol. 20, no. 2, pp. 367-377, 2004.

[66] S. Cosnier, C. Mousty, X. Cui, X. Yang, and S. Dong, "Specific determination of $\mathrm{As}(\mathrm{V})$ by an acid phosphatase-polyphenol oxidase biosensor," Anal. Chem., vol. 78, no. 14, pp. 4985-4989, 2006. 
Asma Soussou received the degree in materials and nanostructures from the Sciences Faculty of Monastir, Tunisia, in 2012, and the Ph.D. degree in physics (lasers, matter, and nanosciences) from the University of Bordeaux, France, and the University of Monastir, Tunisia, in 2016. She was involved in research at LOMA, the Laboratoire de Microélectronique et Instrumentation, Monastir, and INRAP, Tunis. In 2017, she started a temporary assistant-teacher position at the Leonard De Vinci Graduate School of Engineering, ESILV.

Ibtissem Gammoudi received the Ph.D. degree in chemistry and electronics from the Université de Bordeaux, France, and the FSM, Tunisia, in 2012 From 2013 to 2015, she held a temporary position in teaching and research with the Université de Bordeaux. She currently manages the Nanophynov technology transfer cell focusing on the design of micro-biosensors for various applications at LOMA.

Fabien Moroté received the technical degree in physics from the Université de Bordeaux, France, in 2007, and the B.Sc. degree in physical measurements from Albi University in 2008. In 2008, he was with the Technical Staff, LOMA, where he is in charge of the Nano-Spectro-Imaging technical platform.

Adel Kalboussi received the Ph.D. degree in physics from Claude-Bernard University, Lyon, France, in 1990. After six years, he qualified as a University Lecturer from INSA-Lyon and Tunis University and became a Professor with FSM, Tunisia, in 2002. Since 1997, he has been leading the Characterization and Simulation of Electronic Materials and Devices Group, Laboratoire de Microélectronique et Instrumentation, FSM, Tunisia.
Touria Cohen-Bouhacina received the Ph.D. degree in electronics from Paul Sabatier University, Toulouse, France, in 1989. She became an Assistant Professor of Physics with Bordeaux 1 University, France, in 1991, where she was a Professor in 2005. She currently leads the BioPhyNa Group, LOMA, where she developed different applications of atomic force microscopy, applying this method to various topics, such as the physicochemical treatments of surfaces and their nanomechanical properties or the hydrodynamics in the vicinity of surfaces. She also developed experiments on soft systems, such as polymers and biological systems (ATP synthase, cells, and bacteria).

Christine Grauby-Heywang received the degree in biochemistry and molecular biophysics and the Ph.D. degree in molecular biophysics from Paris 6 University, France, in 1998. She was an Assistant Professor at ParisNord University, France, and a post-doctoral position of one year with the Sackmann's Group, Technische Universität München, Germany. She became an Assistant Professor with Bordeaux 1 University, France, in 1999, where she teaches mainly physics. She is a member of the BioPhyNa Group, LOMA. Her research fields concern mainly Langmuir monolayers and supported films made of lipids or organic molecules such as functionalized hemicyanines with particular optical properties, in collaboration with Russian colleagues from the Frumkin Institute, Moscow. She turned a few years ago to the interaction of nanoparticles with membrane models and to the development of biosensors.

Zouhair M. Baccar was born in Tunis, Tunisia, in 1970. He received the $\mathrm{Ph} . \mathrm{D}$. degree in integrated electronic devices from the Ecole Centrale de Lyon, France, in 1996. He was an Assistant Professor with many Tunisian universities. In 2013, he received the Certification to Supervise Research HDR from the University of Tunis El Manar, Tunisia. Since 2008, he has been a Senior Researcher with INRAP and led the Nanobioengineering Group. He was the contact point of INRAP, AUF Agency, and the AVERROES EU-Program. $\mathrm{He}$ also initiated an institutional partnership with the National Academy of Sciences, Kiev, Ukraine. In 2015, he was an Associate Professor with the Tunisian Military Academia of Fondouk Jedid, Ministry of Defense, Tunisia. His current research activity is focused on synthesis and characterization of LDH nanoparticles, nanomagnets and hybrid nanomaterials, surface coating and biomembranes, and development of biosensors for biomedical and safe food monitoring applications. He was the PI of several bilateral projects with Spain (AECI and AECID) and Morocco. 